\title{
ESTRATÉGIAS DE COMUNICAÇÃO PARA A ATENUAÇÃO DE DANOS À REPUTAÇÃO EM CRISES ORGANIZACIONAIS
}

\section{ARTIGO ORIGINAL}

ABDALAH, Mateus Nunes ${ }^{1}$

ABDALAH, Mateus Nunes. Estratégias de comunicação para a atenuação de danos à reputação em crises organizacionais. Revista Científica Multidisciplinar Núcleo do Conhecimento. Ano. 06, Ed. 12, Vol. 02, pp. 140-151. Dezembro de 2021. ISSN: 2448-0959,

Link

de acesso:

https://www.nucleodoconhecimento.com.br/comunicacao/estrategias-decomunicacao,

DOI:

10.32749/nucleodoconhecimento.com.br/comunicacao/estrategias-de-comunicacao

\section{RESUMO}

A utilização adequada da comunicação durante uma crise organizacional tem a capacidade de amenizar danos à reputação de uma empresa e contribuir com a manutenção de suas operações e relacionamento com seus públicos de interesse. Neste contexto, o presente artigo, tem como questão norteadora: quais estratégias de comunicação podem ser utilizadas com maior eficácia para minimizar o impacto negativo à reputação de uma empresa em uma crise corporativa? Tendo como objetivo apontar as estratégias de comunicação mais efetivas para a gestão de crises corporativas. Para isto, foi realizada uma coleta de dados de pesquisas de autores da área de comunicação e análise de casos reais de crises passadas. Como resultados, conclui-se que as principais indicações foram que as organizações devem planejar antecipadamente a sua gestão de crise, e fazê-la de forma orientada para o bem-estar das vítimas, mantendo a transparência e um fluxo constante de informações pertinentes.

\footnotetext{
${ }^{1}$ Graduação em Comunicação Social com Habilitação em Publicidade e Propaganda. ORCID: 0000-0002-79426359.
}

RC: 102833

Disponível em: https://www.nucleodoconhecimento.com.br/comunicacao/estrategiasde-comunicacao 
Palavras-chave: comunicação, gestão de crise, reputação, stakeholders.

\section{INTRODUÇÃO}

A comunicação tem um papel essencial na gestão de uma crise que assola uma organização e potencialmente prejudica sua imagem e reputação perante seus stakeholders. Segundo Coombs (2015), uma gestão eficaz de crise pode retirar a organização mais rapidamente do período de instabilidade e fortalecer a confiança de seu público estratégico; ao passo que, se gerida inadequadamente, a crise pode resultar em danos irreparáveis à reputação da empresa.

Neste contexto, o presente artigo, tem como questão norteadora: quais estratégias de comunicação podem ser utilizadas com maior eficácia para minimizar o impacto negativo à reputação de uma empresa em uma crise corporativa? Tendo como objetivo, através da revisão das obras de autores e pesquisadores do ramo da comunicação e estudos de caso, apontar as estratégias de comunicação mais efetivas para a gestão de crises corporativas.

\section{DESENVOLVIMENTO}

A definição de crise engloba vários conceitos, os quais nem todos estão relacionados com o objetivo do presente artigo. O dicionário Michaelis fornece diversos significados para o termo. Entre eles inclui-se um "momento de maior intensidade de uma dor em um órgão ou parte circunscrita do corpo" e "ausência ou deficiência de algo; carência, escassez, falta" (CRISE, 2021).

Antes de abordar as diferentes estratégias de comunicação em uma crise, é importante, portanto, definir exatamente o que configura uma crise sob o ponto de vista organizacional. Coombs (2015) define uma crise organizacional como uma ameaça às operações ou reputação de uma organização, que pode gerar consequências negativas para a própria organização ou seus públicos de interesse, se não for administrada apropriadamente. 
A crise organizacional pode ser subdividida em crise operacional e crise de reputação (COOMBS, 2015). A crise operacional é aquela que afeta os meios de produção - como um acidente envolvendo a empresa ou a necessidade de recall em massa de um produto defeituoso. Já a crise de reputação não prejudica diretamente os meios de produção, mas afeta a imagem da empresa perante seus stakeholders um exemplo cada vez mais comum na era das mídias sociais é uma ação que seja percebida como ofensiva por parte do público.

Outra importante definição a ser feita no âmbito da administração de uma crise organizacional é a distinção entre imagem e reputação.

Segundo Argenti e Forman (2002), a imagem de uma instituição é estabelecida pela percepção que seus públicos de interesse têm dela, sendo afetada pela comunicação realizada pela organização e por experiências que cada pessoa tem com esta. Pode-se concluir que a imagem que se possui de uma empresa é distinta de um indivíduo para o outro, e pode variar de um momento para outro, baseado na exposição recente desta pessoa com a instituição.

Já a reputação corporativa, como definida por Fombrun (1996), é uma percepção coletiva que os stakeholders da organização têm de suas ações passadas e perspectivas futuras, e representa a associação emocional que seus públicos de interesse, como um todo, fazem com a marca.

\subsection{ESTRATÉGIAS DE COMUNICAÇÃO}

A equipe de gestão de uma organização deve se preparar antecipadamente para potenciais crises, estudando as possibilidades de instabilidades e traçando um planejamento com táticas comunicacionais e operacionais, que sejam adequadas à instituição, nas diferentes circunstâncias de crise que esta possa se envolver. (BERNSTEIN, 2016).

Segundo Bernstein (2016), há dois efeitos imediatos em adotar esta antecipação de crise: pode-se identificar maneiras de prevenir crises iminentes ou potenciais; e

RC: 102833

Disponível em: https://www.nucleodoconhecimento.com.br/comunicacao/estrategiasde-comunicacao 
pode-se traçar respostas para crises futuras sem a pressão de estar efetivamente lidando com elas.

Com a ocorrência do evento danoso, não apenas o conteúdo da comunicação precisa ser eficiente, mas também o momento de sua aplicação há de ser correto. É necessário ser tempestivo e transparente para informar ao público sobre a existência e conteúdo de um evento de instabilidade institucional, e evitar a tendência de esconder e ignorar a situação.

De acordo com pesquisas realizadas por Claeys e Cauberghe (2012), quando a própria organização é a primeira a informar ao público uma crise que a envolva, ocorrem danos menores à sua reputação do que se a crise fosse reportada por uma fonte externa. Esta ideia é baseada em um conceito jurídico que foi aplicado à comunicação, conhecido em inglês como stealing thunder ("apropriação do holofote", em tradução livre), em que se considera que, quando há uma "fraqueza" na defesa do réu, esta será menos prejudicial, quando da elaboração da sentença, se for levantada pelos seus advogados de defesa do que pelos advogados de acusação (WILLIAMS; BOURGEOIS; CROYLE, 1993). Em outras palavras, é mais vantajoso admitir uma falha oportunamente, do que omitir-se e ser posteriormente acusado por terceiros.

É importante também analisar a estratégia oposta e seus impactos. O método de negação foi, e ainda é bastante utilizado por gestores em situações de crise, com resultados que podem ser bastante imprevisíveis, visto a quantidade de variáveis das quais sua eficácia depende. O método consiste basicamente na ideia de que, caso não seja percebido o envolvimento de uma organização em uma crise, sua reputação não pode ser prejudicada. Conforme afirma Benoit (1994), estudos indicam que esta estratégia de negação é capaz de reduzir o dano à reputação de uma instituição porque elimina a conexão entre esta e a crise.

No entanto, como afirmado anteriormente, a eficácia deste método depende de outras variáveis e da circunstância do caso, ficando cada vez menos previsível e 
mais longe do controle do gestor. Se for apontado, de alguma forma, que a organização possui uma relação com o fato gerador da crise, mesmo que pequena, o prejuízo à reputação e o ceticismo dos stakeholders é exacerbado. Este é um acontecimento que, conforme afirma Grebe (2013), pode gerar uma crise dupla uma situação em que a própria resposta da organização a uma crise gera uma segunda crise. Além disso, uma resposta inadequada da gestão de crise afetará também situações de instabilidade futuras, mesmo que sem qualquer relação com a atual. Afinal, a perda de credibilidade - como percebida pelo público - gerada por uma ausência de transparência em um momento crítico dificilmente é revertida no futuro, gerando um fluxo de desconfiança que acompanhará a organização em suas atividades posteriores (GREBE, 2013).

Após assumir sua parcela de responsabilidade e tomar a iniciativa de ser o primeiro a informar a crise aos públicos de interesse, é necessário adotar uma forma de comunicação.

Uma crise organizacional em geral envolve vítimas, que podem ser afetadas pelas atividades da instituição de diferentes formas. $O$ objetivo da comunicação é manter a confiança destas vítimas e demais públicos estratégicos apesar dos impactos negativos que a crise possa ter provocado. Para alcançar esse fim, conforme apontam Claeys e Cauberghe (2012), a comunicação deve ser orientada para as vítimas, com o estabelecimento de um fluxo regular de informações e a divulgação das medidas que estão sendo tomadas pela organização para auxiliar os afetados e amenizar as consequências geradas pela crise. A própria comunicação é, por si, uma providência para atenuar consequências, através de alertas ao público sobre detalhes do evento e a recomendação de medidas que devem ser tomadas por cada setor para evitar que os danos se alastrem ou para prevenir uma repetição da crise (COOMBS, 2015). Assumir a responsabilidade não consiste apenas em admitir culpa; envolve tomar os passos necessários para reduzir os prejuízos causados à sociedade, e a comunicação é uma parte integral deste projeto. 
É importante analisar a estratégia de controle da narrativa durante a crise. Neste contexto, Moran e Gregory (2014) investigaram as consequências para a reputação corporativa advindas de duas estratégias antagônicas: a de se manter em silêncio e a de se comunicar intensamente com os stakeholders. Na primeira, apesar da associação da empresa com a crise ficar menos presente na consciência do público a curto prazo, a instituição sofre um declínio maior no seu valor de marca a longo prazo, e leva mais tempo para se recuperar.

As organizações em que os gestores mantiveram um fluxo de informação constante direcionado aos seus públicos, mantendo-se sempre como o primeiro a divulgar atualizações, obtiveram uma recuperação mais veloz em sua reputação e valor de marca (MORAN; GREGORY, 2014). Especialmente neste período de facilidades tecnológicas e abundância de informações em tempo real ao alcance de virtualmente qualquer pessoa, estar no controle do que é oficialmente divulgado é fundamental para transmitir a imagem que a empresa deseja. Períodos longos de inatividade comunicacional geram margem para inquietação e especulação, fazendo com que a percepção sobre as ações da organização seja moldada por terceiros.

Neste âmbito, é também importante combater as notícias falsas e informações incompletas que produzem uma imagem errônea sobre a crise e as medidas tomadas pela organização. Esta, na realidade, é a situação em que a tática da negação pode ser bem utilizada. Segundo Kimmel e Audrain-Pontevia (2010), os gestores devem responder agressivamente a crises de desinformação. Não deve ser permitido que informações falsas sejam aceitas como fatos, o que é mais plausível de ocorrer quando elas não são rapidamente contestadas.

\subsection{AÇÕES PÓS-CRISE}

É difícil determinar um ponto em que a crise possa ser considerada finalizada. Segundo Zemke (2020), pode-se estabelecer que ações pós-crise podem ser tomadas quando a organização começa a verificar uma estabilidade. 
Nesta etapa, é importante que a comunicação esteja focada para o futuro da empresa, de forma a amenizar as incertezas naturais dos stakeholders advindas do período de instabilidade. A organização precisa integrar às suas comunicações os aprendizados e medidas que foram e continuarão a ser implementadas para evitar a instauração de uma nova crise, fortalecendo uma nova imagem que ajude a instituição a reparar, ao longo do tempo, os danos que foram causados a sua reputação. Concomitantemente, é importante realizar pesquisas para entender qual foi a mudança nas expectativas dos seus públicos, realizando ajustes na sua comunicação e em suas operações (ZEMKE, 2020).

Internamente, a gestão deve elaborar um debriefing, com a análise das providências que foram tomadas, quais foram corretas ou realizadas inadequadamente, e seus resultados. Esses elementos irão auxiliar na prevenção e no planejamento da gestão de novas crises que poderão atingir a organização no futuro (BERNSTEIN, 2016).

\subsection{CASOS}

\subsubsection{TYLENOL}

Em 1982, a adulteração criminosa de cápsulas do fármaco Tylenol - ainda hoje um dos mais renomados medicamentos analgésicos do mundo - resultou na morte de 7 pessoas na região metropolitana de Chicago, nos EUA, por envenenamento por cianeto de potássio. Não houve nenhum suspeito indiciado ou condenado pelas mortes (FLETCHER, 2009).

A altíssima gravidade do caso, envolvendo a morte de consumidores, poderia ter lesado irreparavelmente a empresa Johnson \& Johnson, proprietária do medicamento. No entanto, tornou-se uma das maiores referências em gestão e comunicação de crise, e modificou normas da indústria farmacêutica e a forma com que medicamentos são consumidos. 
A primeira atitude da empresa, ao descobrir que as fatalidades estavam sendo causadas pelo consumo de cápsulas de Tylenol, foi ordenar imediatamente o recall de 31 milhões de embalagens do produto, e iniciar uma campanha de comunicação em massa alertando o público para não consumir este medicamento. A organização também ofereceu medicamentos substitutos gratuitamente para os consumidores que devolvessem suas embalagens. Apesar do recall não ter sido capaz de retirar todos os remédios adulterados de circulação - algumas embalagens envenenadas ainda foram descobertas em farmácias e mercados posteriormente -, a comunicação garantiu que estes não tivessem sido vendidos ou consumidos (MARKEL, 2014).

A Johnson \& Johnson tomou a iniciativa de ser também uma fonte de informações confiáveis sobre o caso, e manteve seus públicos informados com atualizações frequentes da investigação, além de oferecer recompensas para informações que levassem a apreensão dos responsáveis pelo envenenamento (RUÃO, 2020). Segundo Markel (2014), uma das conclusões alcançadas rapidamente pela apuração da empresa foi que a introdução do cianeto às cápsulas ocorreu após a saída do produto da fábrica.

Em relação a medidas para evitar novas calamidades, a empresa desenvolveu, junto com repartições governamentais da área sanitária, no prazo de um mês, embalagens à prova de adulteração e lacres de alumínio e outros recursos capazes de alertar visualmente o consumidor sobre uma possível adulteração do produto, antes que este fosse utilizado. Essas medidas de proteção tornaram-se prática padrão na indústria farmacêutica e alimentícia (MARKEL, 2014).

Os esforços de comunicação, aliados aos desenvolvimentos de novos métodos de produção e os prejuízos causados pelo recall de produtos, resultaram em investimentos de mais de 100 milhões de dólares realizados pela empresa devido à crise. Antes desta, o remédio Tylenol representava mais de $35 \%$ do mercado de analgésicos sem prescrição médica nos Estados Unidos, sofrendo uma queda para menos de $8 \%$ algumas semanas após os envenenamentos (MARKEL, 2014). 
Conquanto, as medidas eficientes para impedir o alastramento do problema e sua repetição, e a comunicação que fortaleceu a imagem de que a empresa estava mais interessada no bem-estar e segurança de seus consumidores do que em lucros imediatos, fizeram com que a Johnson \& Johnson saísse da crise com sua reputação fortalecida, enquanto o Tylenol voltou a representar $30 \%$ do mercado de analgésicos over-the-counter norte-americano dentro de um ano (RUÃO, 2020). Hoje, a crise do Tylenol de 1982 é mais lembrada como um caso bem-sucedido de gestão de crise do que um dano devastador à empresa, apesar da extrema gravidade dos acontecimentos que a envolveram.

\subsubsection{BAR QUITANDINHA}

No carnaval de 2016, um bar localizado na Vila Madalena, em São Paulo, foi envolvido em uma polêmica que viralizou após uma cliente relatar, através de sua rede social, um assédio sofrido dentro das dependências do estabelecimento, e as providências consideradas inaceitáveis que foram tomadas pela gerência do local. $O$ caso evidencia a capacidade e a velocidade que as redes sociais possuem de realçar as fraquezas de uma empresa e impulsionar uma crise, e que a necessidade de planejamento e treinamento de crise não é algo exclusivo das gigantes multinacionais.

Em fevereiro de 2016, Júlia Velo, uma cliente do bar Quitandinha, postou, em sua página de Facebook, um relato do que ocorreu com ela e uma amiga na noite anterior. Segundo sua postagem, dois homens se sentaram a sua mesa sem obter permissão e começaram a importuná-las, de forma cada vez mais agressiva. Ao solicitar a intervenção do gerente e dos garçons, esses rapidamente se aliaram aos supostos agressores - que os eram conhecidos - e expulsaram as duas supostas vítimas do local (VELO, 2016). De acordo com a revista Exame (2016), a postagem viralizou celeremente, sendo compartilhada mais de 40 mil vezes por usuários inconformados com a situação. 
Sem buscar atribuir nenhum juízo de valor relacionado com a postagem original da autora do relato, o presente artigo pretende, nos parágrafos a seguir, analisar a resposta da equipe de comunicação do bar em sua gestão desta crise.

A gestão do bar demorou quase 24 horas para se pronunciar sobre o ocorrido. Com a velocidade na qual o caso se espalhou pelas redes sociais, esta demora foi grande demais para permitir que o estabelecimento pudesse ter algum controle da narrativa (RODRIGUES, 2016). Ademais, transmitiu uma imagem de que a preocupação da empresa em esclarecer a situação só ocorreu quando ela viu suas atividades ameaçadas, e não por uma consideração pelo bem-estar de sua cliente e demais públicos.

O pronunciamento da empresa foi completamente oposto a uma comunicação orientada para a vítima. Pelo contrário, a gestão do bar procurou, em sua postagem, tirar a credibilidade da vítima, sem qualquer argumento contundente que corroborasse sua versão. Foi feita uma tentativa de negação do ocorrido, mas seu fundamento não era baseado em fatos e provas, e sim em pretextos superficiais que não possuem qualquer relação com o evento que transcorreu, como a antiguidade do local e o fato de que uma grande parcela de seus clientes eram mulheres (RODRIGUES, 2016). Não ficou visível nenhuma tentativa de efetivamente investigar o ocorrido para que houvesse uma resolução justa e uma compensação pudesse ser oferecida às vítimas.

A comunicação da empresa gerou ainda mais indignação do público em geral, com ainda mais repercussão negativa (EXAME, 2016). Foi uma situação de crise dupla. O foco agora não era somente no episódio ocorrido dentro do estabelecimento, mas também a forma com que a empresa decidiu abordar a situação causou repúdio. $\mathrm{A}$ empresa foi rotulada negativamente e viu usuários deixarem comentários e avaliações desfavoráveis em suas redes sociais e ferramentas de avaliação - um indicador mensurável do declínio de sua reputação. 


\section{CONSIDERAÇÕES FINAIS}

A comunicação desempenha uma função indispensável dentro da gestão de uma crise corporativa. O presente artigo buscou apontar as estratégias comunicacionais mais efetivas para a gestão desta categoria de crise, com base em sua questão norteadora, retomada a seguir: quais estratégias de comunicação podem ser utilizadas com maior eficácia para minimizar o impacto negativo à reputação de uma empresa em uma crise corporativa? Em resposta, foi possível verificar a importância de um planejamento de crise e treinamento dos colaboradores antes mesmo de ocorrer qualquer instabilidade institucional deve ser enfatizada. É um equívoco acreditar que o planejamento de comunicação de crise se limita às equipes de empresas de grande porte, como foi evidenciado na análise do prejuízo reputacional do bar Quitandinha.

Conforme apontam os autores citados no texto, a empresa deve buscar ser a primeira a informar os seus stakeholders sobre o evento causador da crise, de forma transparente, mas com a cautela de controlar a narrativa e impedir que notícias falsas circulem sem contestação. Sua comunicação deve ser orientada para a manutenção do bem-estar das vítimas e divulgação das medidas tomadas para o abrandamento dos danos causados.

Ao começar a verificar um retorno de estabilidade, a comunicação externa deve ser orientada para o futuro da organização e em ajustar sua mensagem às novas expectativas dos stakeholders. Internamente, deve ser feita uma revisão das táticas comunicacionais utilizadas durante o período de instabilidade, para que o planejamento de crise seja aprimorado para o futuro.

\section{REFERÊNCIAS}

ARGENTI, Paul; FORMAN, Janis. The Power of Corporate Communication Crafting the Voice and Image of Your Business. $1^{\text {a }}$ ed. New York: McGraw-Hill, 2002. 
BENOIT, William. Accounts, excuses, and apologies: $A$ theory of image restoration. $1^{\text {a }}$ ed. Albany: State University of New York Press, 1994.

BERNSTEIN, Jonathan. The 10 Steps of Crisis Communications. Bernstein Crisis Management, 2016. Disponível em: < https://www.bernsteincrisismanagement.com/the-10-steps-of-crisis-communications/ >. Acesso em: 06 nov. 2021.

CLAEYS, An-Sophie; CAUBERGHE, Verolien. Crisis response and crisis timing strategies, two sides of the same coin. Public Relations Review, 38(1), 83-88, 2012.

COOMBS, Timothy. Ongoing crisis communication: Planning, managing, and responding. $4^{\mathrm{a}}$ ed. Thousand Oaks, CA: Sage, 2015.

CRISE. In: Michaelis, Dicionário Brasileiro da Língua Portuguesa, 2021. Disponível em: < https://michaelis.uol.com.br/moderno-portugues/busca/portuguesbrasileiro/crise/ >. Acesso em: 04 nov. 2021.

EXAME. O que o caso do bar Quitandinha ensina sobre redes sociais. Exame, São Paulo, 17 fev. 2018. Disponível em: < https://exame.com/pme/o-que-o-caso-dobar-quitandinha-ensina-sobre-redes-sociais/ >. Acesso em: 27 nov. 2021.

FLETCHER, Dan. A brief history of the Tylenol Poisonings. Time, 09 fev. 2009. Disponível em: < http://content.time.com/time/nation/article/0,8599,1878063,00.html >. Acesso em: 27 nov. 2021.

FOMBRUN, Charles. Reputation: realizing the value from the corporate image. $1^{\mathrm{a}}$ ed. Boston, MA: Harvard Business School Press, 1996.

GREBE, Sacha Karl. Things can get worse: How mismanagement of a crisis response strategy can cause a secondary or double crisis: the example of the 
AWB corporate scandal. Corporate Communications: An International Journal, 18(1), 70-86, 2013

KIMMEL, Allan; AUDRAIN-PONTEVIA, Anne-Françoise. Analysis of commercial rumors from the perspective of marketing managers: Rumor prevalence, effects, and control tactics. Journal of Marketing Communications, 16(4), 239253, 2010.

MARKEL, Howard. How the Tylenol murders of 1982 changed the way we consume medication. PBS News Hour, 29 set. 2014. Disponível em: < https://www.pbs.org/newshour/health/tylenol-murders-1982 >. Acesso em: 08 nov. 2021.

MORAN, Robert; GREGORY, James. Post crisis: Engage—or fly low? Brunswick Review, 8, 32- 34, 10 mar. 2014. Disponível em: < https://www.brunswickgroup.com/media/2056/post-crisis.pdf >. Acesso em: 28 nov. 2021.

RODRIGUES, J. C. O que fez de errado o Quitandinha Bar (além do óbvio)? Webinsider, 2016. Disponível em: < https://webinsider.com.br/o-que-fez-de-errado-oquitandinha-bar-alem-do-obvio/ >. Acesso em 09 nov. 2021.

RUÃO, Teresa. O caso tylenol e o valor da comunicação de crise: é tempo de colocar as pessoas em primeiro lugar. Communitas, 01 abr. 2020. Disponível em: < https://www.communitas.pt/ideia/o-caso-tylenol-e-o-valor-da-comunicacao-de-crisee-tempo-de-colocar-as-pessoas-em-primeiro-lugar/ >. Acesso em 08 nov. 2021.

VELO, Júlia. O Carnaval começou com uma dose cavalar de silenciamento. São Paulo, 05 fev. 2016. Facebook: julia.velo. Disponível em: < https://www.facebook.com/julia.velo/posts/1027796097294719 >. Acesso em: 27 nov. 2021. 
WILLIAMS, Kipling; BOURGEOIS, Martin; CROYLE, Robert. The effects of stealing thunder in criminal and civil trials. Law and Human Behavior, 17(6), 597-609, 1993.

ZEMKE, Ayme. Role of strategic communication in crisis management and business continuity. Behive Strategic Communication, 13 jun. 2020. Disponível em: < https://beehivepr.biz/strategic-communication-in-crisis/ >. Acesso em: 27 nov. 2021.

Enviado: Novembro, 2021.

Aprovado: Dezembro, 2021. 